\title{
PATTERN AND CHARACTERISTICS OF MIGRATION FROM BIHAR: EVIDENCE FROM CENSUS DATA
}

\begin{tabular}{|c|c|}
\hline Shreya Nupur & $\begin{array}{c}{ }^{1} \text { Research Scholar, Department of Humanities and } \\
\text { Social Sciences, Indian Institute of Technology Patna, } \\
\text { Bihar, India }\end{array}$ \\
\hline Kumari Youkta & $\begin{array}{c}{ }^{2} \text { Research Scholar, Department of Humanities and } \\
\text { Social Sciences, Indian Institute of Technology Patna, } \\
\text { Bihar, India, }\end{array}$ \\
\hline
\end{tabular}

\section{ABSTRACT}

Article DOI URL: https://doi.org/10.36713/epra5425

Migration is closely linked to development process. Due to the stagnant development process in Bihar outmigration have increased in recent two decades. It has it's root in green revolution which continued till date. Migration refers to movement of people from one place to another. When a person is enumerated at different place than his/her place of birth is known as migrant. It may be of permanent or temporary, a short or long term in nature. Several scholars in their studies showed that poor implementation of land reforms, as well as a lack of industrial investments in Bihar, left the state underdeveloped. Low Growth, high levels of poverty and the 'semi-feudal' systems of agricultural production, where the upper castes-controlled land and power, encouraged outmigration. Due to ongoing political, social and economic changes in Bihar, the migration pattern is also changing in past decades. This paper aims to analyse the pattern and causes of migration in Bihar through secondary data sources such as Census of India 2001 and 2011, by using tools like Percentage, ratio, pie chart, histogram, graphical presentation etc. Motivation to this study is to draw attention of policymakers because Outmigration of human capital is important developmental challenge for Bihar. There is urgent need to protect and develop village industries in Bihar which in turn create employment and reduce migration through spill over effect.

KEYWORDS: Outmigration, pattern, employment, Bihar, Government policy, Developmental challenge JEL Classification: D33, E24, F24, F63, I18

\section{INTRODUCTION}

We live in the Age of Migration. Over the years, the process of migration has accelerated, diversified and become increasingly politicised. With developing urbanization process in developing countries the phenomenon of rural to urban migration also took pace. Migration is the response of individuals to better opportunities that (s)he could get by mobility. Development economists such as Lewis (1954) and Fei and Rains (1964) well-thought-out rural to urban migration as an important phenomenon which can contribute to the economic development of countries. the Harris-Todaro model anticipated that urbanization would become a stable and 'mainstreamed' characteristic of social life, due to migrants' expectation of jobs and high standard of living in the cities. In the last two decades, the researcher has shifted their focus from rural to rural stream of migration to rural to urban.

After the colonial era several attempts have been made to mitigate the regional disparity in the country. Mixed success has been achieved but Bihar could not grab this opportunity and lagged behind, remain one of most underdeveloped region of India. 
The root cause of underdevelopment of this state is unstable political system and skewed land distribution with few large landholders. Bihar is predominantly an agriculture based state, over the period of time agricultural productivity has declined forcing people to search for other non-farm activities for survival. Migration is also one of the survival strategy, particularly in rural areas where people are engaged in agricultural activity and try to find jobs in lean season. When these people reach to urban centres they generally get employment in informal sector as daily wage labourers. Their problems increase at destination as well as at origin because they live in the shortage of productive assets and capital which deprived them from any new economic opportunities. In Bihar migration is not a desire but only way to cope up in the difficult situation such as flood in Bihar.

All the segments of the society in Bihar are participating in out-migration. It appears higher among those associated with agriculture, with small or marginal landholdings. Male out-migration from the state is taking place from the household, while household is not leaving the other member for income generating activities. Therefore, migration process is generating a diverse livelihood at the area of origin, particularly among the agricultural household. In recent years trend of migration is changing female migration is increasing other than the reason of marriage while male outmigration has declined as compared to last decades still extent of outmigration is very high which needs policy attention by government.

\section{LITERATURE REVIEW}

The beginning of present migration scenario from Bihar have its root in green revolution started in early $1970 \mathrm{~s}$ in north west India. Due to green revolution the demand for labour had increased in that region, given the high demand and low demand people from Bihar stated migrating to Punjab. Soon the region neighbouring Punjab such as Haryana, due to spill over effect also started demanding labour which in turn opened one more avenue for migrants. However, started in 1970s this trend soon declined near 1990s due to several reasons such as terrorism attacks, modernisation of agriculture, changing cropping demand of farmers etc. These factors together suppressed the influx of migrants from Bihar and diverted this influx to other states such as Delhi and Maharashtra (Singh 1995).

Deshingkar et al. (2006) viewed migration as a life cycle strategy, people generally sends their male member from family when they reach at certain age, in return male migrant send remittance to support their family financially.

According to Rath et al. 2008, among four streams of migration the most prevalent is rural to urban migration. 20 million out of 97.5 million are migrants who moved to urban centres with rural background. The attracting urban centres for prospective migrants are Mumbai, Delhi, Kolkata etc.

The majority of migrant population arrives at these destinations belonged to social disadvantaged group. They migrate due to less agricultural productivity and lack of resources such as land at the origin place. In addition to that lack of employment opportunity also trigger migration from rural Bihar. Moreover, due to lack of bargaining power these migrants face exploitations at origin (Gupta 1988; Karan 2003).

Kumar (2009) in his paper emphasized on the issue of hostile condition of migrants from Bihar at the destination place, since significant amount of them come from lower section of society.

There is urgent need to establish industries in the state so that migrants could get job at the native place only but the industrialization is limited to towns near to Patna. Although there are some rural urban linkage but rural hinterland that are far away from town does not get that benefits (Endow 2017).

Although several studies have been conducted to analyse the trend and pattern of Migration from India. There is lack of study that focuses on migration pattern on regional ground such as Bihar. This study focuses on migration pattern from Bihar. Bihar and Uttar Pradesh are major source state of migration due to lack of employment opportunities in these two reasons. Migration from Bihar needs attention of policy makers so that Bihar can use it's Human Capital in efficient way.

\section{OBJECTIVE}

- To analyse the trends and patterns of outmigration from Bihar along with its reasons.

- To analyse the trend and patterns through gendered perspective.

\section{DATA SOURCE AND METHOD APPLIED}

Data Source: We have used Census of India as a data source on migration for the period of 2001-2011 to analyse the trends of outmigration from Bihar.

Methods: In order to study the trends of outmigration, tools such as percentage of total migrants, Rural-Urban distribution of the same and reasons to migrate were analysed through bar graph and pie chart. This study uses the definition of migration given by census, advantage of using this is that it not only capture information about last movement but also about return migration.

\section{RESULTS AND DISCUSSION}

Figure 1 shows the extent of total number of outmigrants and their relative share for this we have used the data from census 2001 and 2011. The figure also highlighted that people are highly migratory in this state with 5.26 million in 2001 to 7.45 million in 
the year 2011. The figure highlighted the point that the share of male population in total migrants of Bihar is more than female with the male share $58 \%$ and female were $42 \%$ of total migrant in 2001 while number of male migrants declined over the decade, in 2011 census $52 \%$ male and $48 \%$ female were migrating.

Figure 2 shows place of destination of out-migrants. The major destinations of out-migrants are Jharkhand
(17.5 percent), West-Bengal (14.5 percent), Delhi (14.5 percent), Uttar Pradesh (14.1 percent), Maharashtra (7.5 percent), Punjab (4.5 percent), Haryana (5 percent), Gujarat (5 percent) and Punjab (4.2 percent). Jharkhand have replaced West-Bengal as a top destination. Delhi is becoming more attractive to migrants. Direction of move have shifted from Punjab, west Bengal to New Delhi and Gujarat

Figure 1: Total number of migrants and their relative share

\section{Total number of migrants and their proportion share}

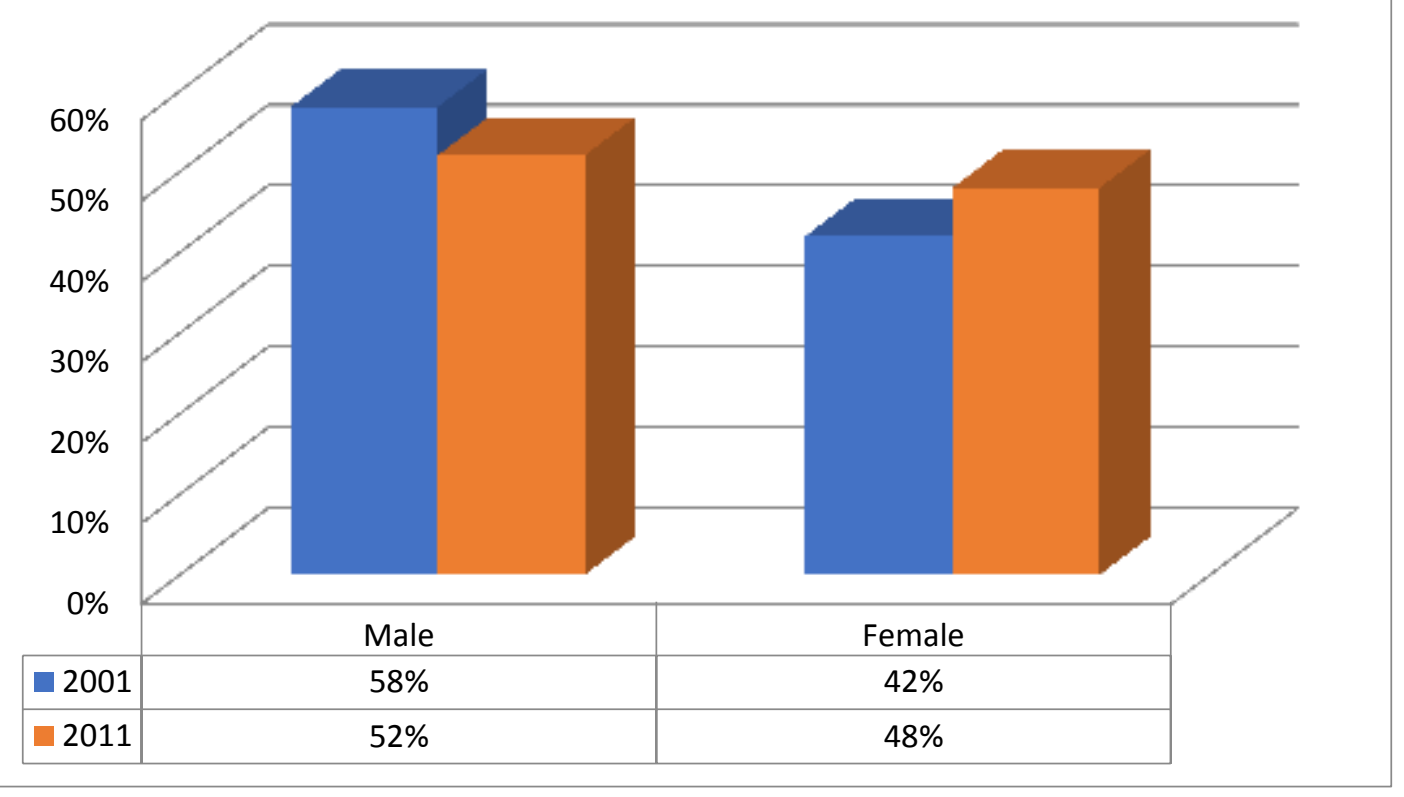

Source: Census of India, 2001 and 2011 


\section{Figure 2: Destination of migrants}

\section{Migrants from Bihar(2011)}

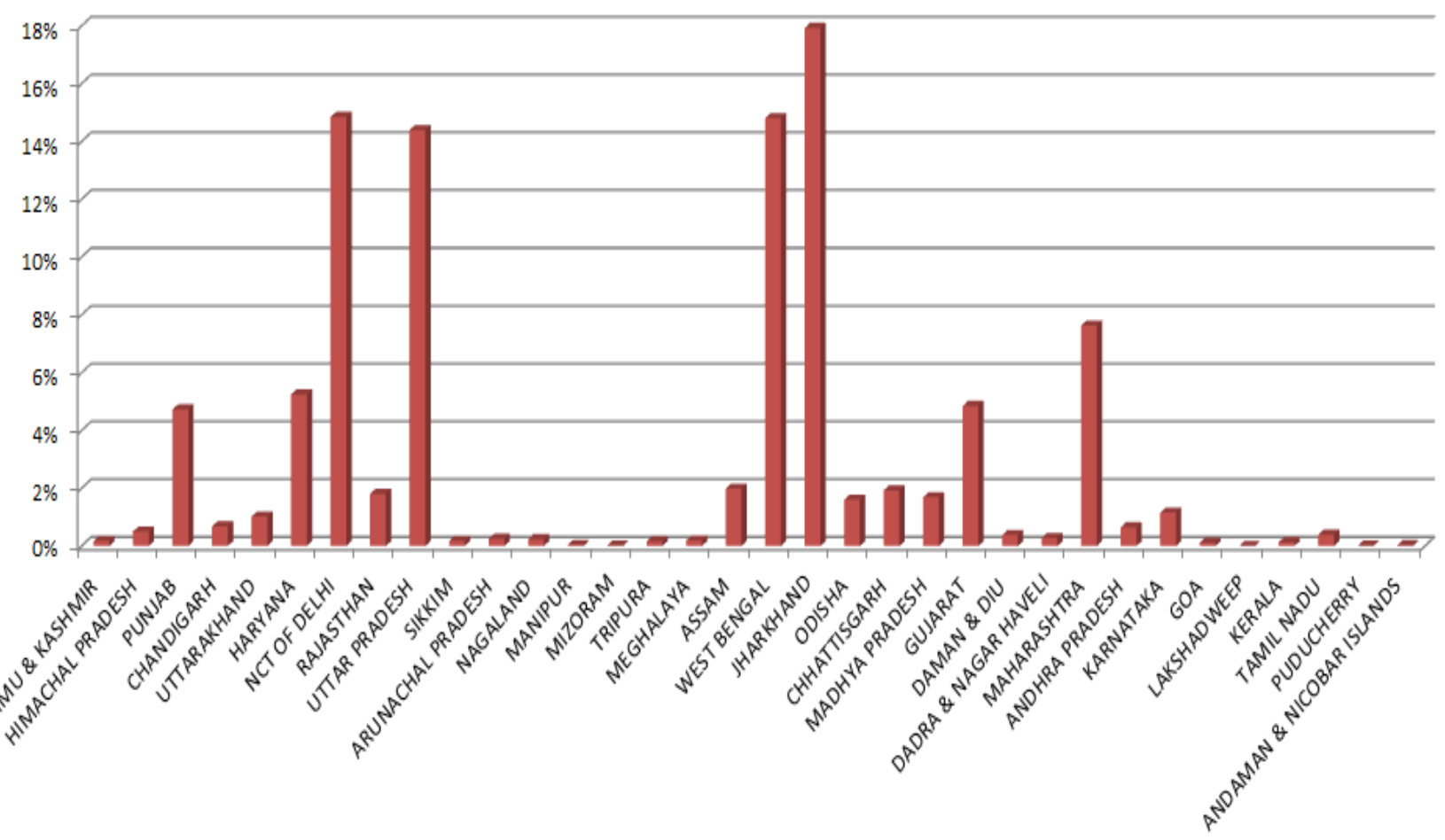

Figure 3 Reasons of Migration by Gender

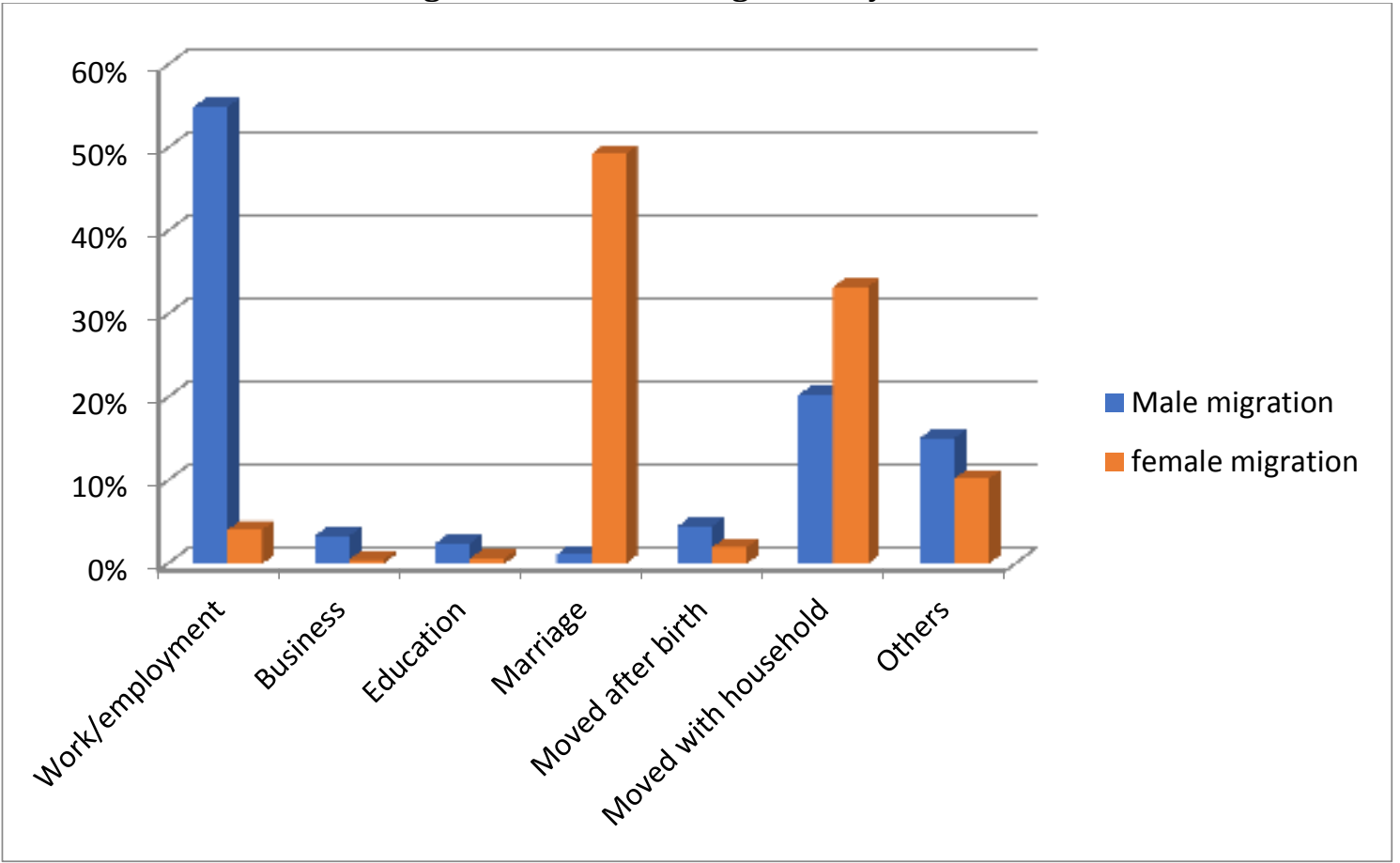

Source: Census of India,2011

According to census, there are six reasons of migration among these reasons migration for work or employment are on the top, then for business, education, mostly females for marriage and moved with household. Figure 3 shows the reasons of migration on the basis of Census, 2011 data. The major portion of male migrates from Bihar exclusively to find out better economic or 
employment opportunity outside the state. When we focus on statics migration in search of work is 60 per cent out of the total out-migrants with 55 per cent male and 5 percent female population. Other important causes of male out-migration is migration of parent or earning member of the family (19\% percent), business $(2 \%$ percent) etc. While biggest reason of female out migration is marriage (47\%), other important reason of female out migration is if they have to move with parent or earning member of family $(33 \%)$.

Figure 4 tells us the several streams of out-migration from Bihar. There are four streams that people take in the process of migration. These are Rural to Urban, Urban to Urban, Rural to Rural and Urban to Rural. Among four streams the Rural to Urban stream dominates with 80 percent followed by Rural to Rural out-migration with a share of 30 percent of total migrants from Bihar. When we talk about Urban to Urban migration stream it is around 19 percent while Urban to Rural migration stream has lowest percentage in total out-migration that is one percent. So in conclusion we can say that outmigration from state of Bihar is dominated by male population towards urban centres and for work purpose.

\section{Figure 4: Streams of Migration from Bihar}

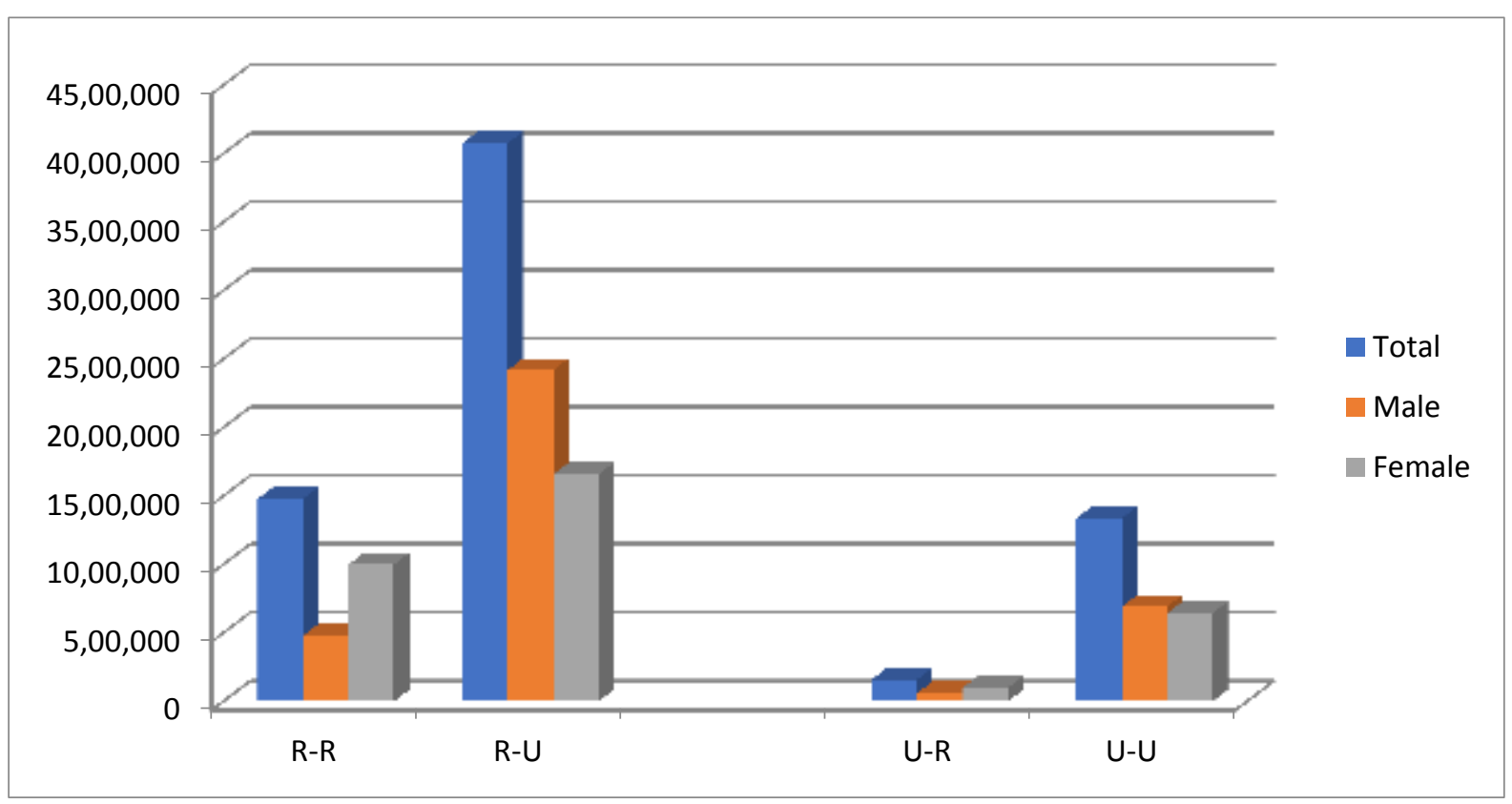

Source: Census of India, 2011 
Figure 5: Change in stream of migration from 2001 to 2011

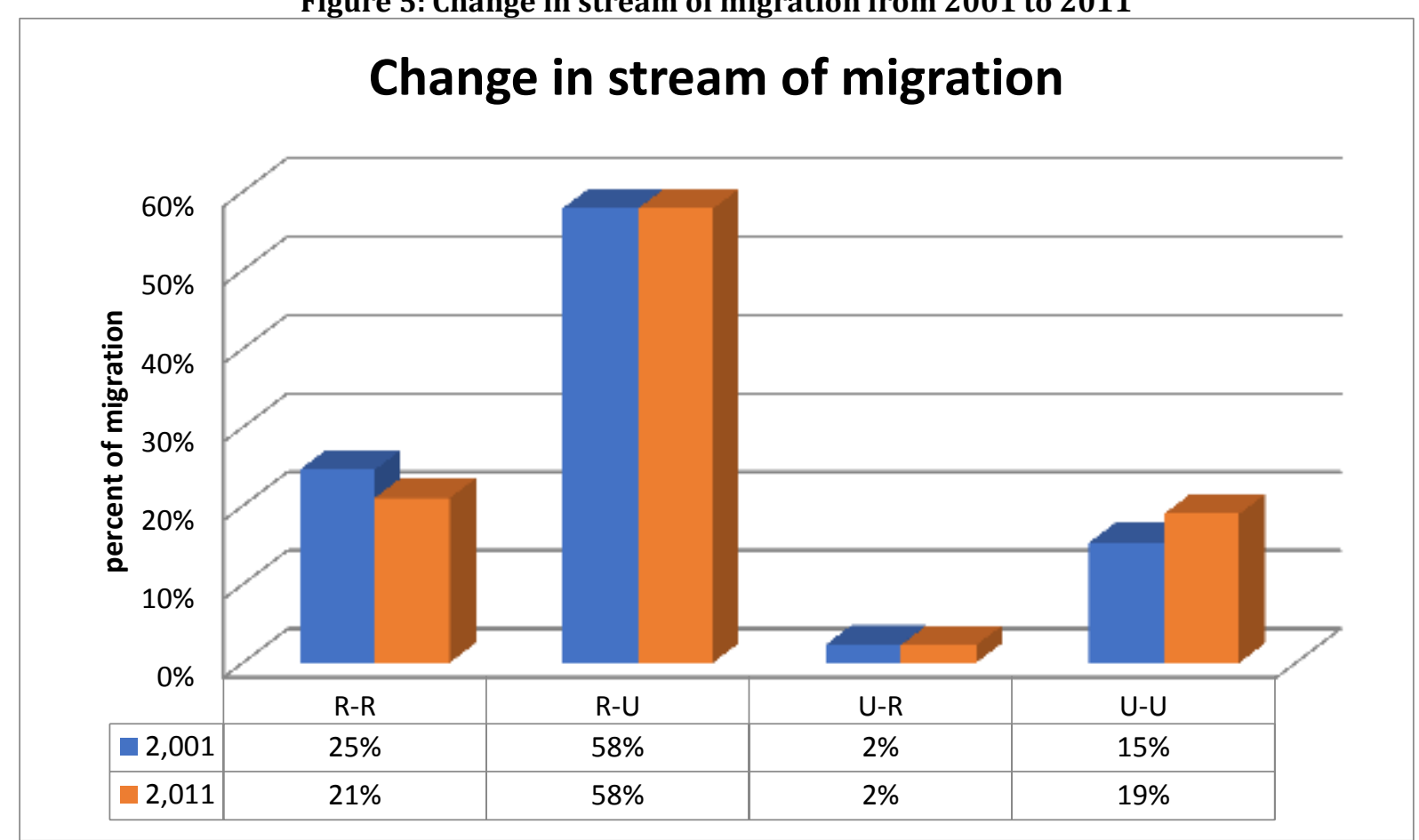

Source: Census of India, 2001 and 2011

Figure 5 shows change in stream of migration over the decade, there is no change in Rural to Urban migration as well as Urban to rural migration. There is increase of Urban to Urban stream of around 4\%, on the other hand there is decline in Rural to Rural migration stream over the decade.

\section{CONCLUSION AND POLICY IMPLICATION}

From the above analysis we can say that the trends of migration from Bihar in last two decades have changed dramatically. During this period not only the proportion of migrants has doubled but also it became widespread. In addition to that the duration of migration has changed from short term to long term.

The volume of out-migration which was 5.26 million, according to census 2001 increased to 7.45 million in the Census 2011, is indeed very large difference, and more than half of population of male migrants for economic or employment related reasons. For female marriage is most important reason of migration but it shows declining trend and an increasing trend is observed in employment in 2011 as compared to 2001, although the increase is not very significant. The states like Delhi, Maharashtra, Punjab, Haryana and Gujarat became an attractive destination for male out-migrants from Bihar and move of the people is mostly taking place towards urban area. When we talk about change in choice of destination over the decades, early 1980 s shows Punjab and Haryana as the most preferred destination. While by the end of 1990s this destination has shifted towards Delhi, Mumbai etc.
People started choosing streams from Rural to Urban in recent decades and the extent of migration have become widespread.

Over the year people have become more aware and get information about destinations through their networks and other sources which in turn reduces their dependency on contractor. This pattern has reduced the exploitation and bad working environment of migrant workers at the destination. However, in few places and kind of work such as construction sites still hire migrant workers through contractor but their role has been minimised.

Given the above backdrop, we know people are migrating due to lack of employment opportunity at origin. So There is urgent need to generate employment opportunities at the origin areas. In the rural areas the major development tool can be investment in small and cottage industries, protection and commercialization of traditional artisan work which have potential to generate employment opportunities and reduce migration from Bihar. There are several schemes such as Jawahar Gram Samridhi Yojana (JGSY), Swarna Jayanti Gramin Swarojgar Yojana (SGSY) etc. have potential to absorb prospective migrants if implemented effectively.

Bihar being one of the top origin state of migrants, should prepare and keep the records and information about migrants and prospective migrants Lack of industrial and agriculture sector development of this state is major cause of migration from this area so only way to reduce the out-migration is to attract investment and rapid economic development of this region is urgent need. Government should focus on attracting investment in service sector and 
should focus on way to increasing productivity of agricultural sector along with development of nonagriculture sector. These efforts can reduce the extent of migration and can retain human capital in the state. In current scenario, Indian economy is going through major economic, political and social changes but due to non-availability of recent data on internal migration several aspects such as impact of remittances and social impact such as Impact on left behind households have not been analysed. Census of India do not provide data on seasonal migration so further study can take into account this issue through other data sources.

\section{REFERENCES}

1. Census of India, (2011). Migration Data from table D1, D2 and D3. http:// www.censusindia.gov.in/2011census/popula tion enumeration.html

2. Deshingkar P., Kumar S., Choubey H. K., Kumar D. (2006). "The role of Migration and Remittances in promoting livelihoods in Bihar". London, Overseas Development Institute.

3. Endow, T. (2017). "Urban development and ruralurban linkages in six towns in Bihar". Final Working Paper, Reference number: C-89113-INB-1. International Growth Centre.

4. Gupta, A.K. (1988). "Sociological Implication of Rural to Rural Migration: A Case Study of Rural Immigrants in Punjab". Allahabad: Vorah Publications

5. Karan, A., (2013), "Patterns of Migration from Rural Bihar", G. lyer (ed.) Migrant Labour and Human Rights in India, pp. 102-39, New Delhi: Kanishka Publishers.

6. Kumar, A. (2009). "A Class analysis of the Bihari Menace". Economic and Political weekly, Volume 44, No. 28(July 11-17, 2009), PP 124-127.

7. Lewis, W. A. (1954). Economic Development with Unlimited Supplies of Labour. The Manchester School, 22(2), 139-191.

8. Ranis, G., \& John C. H. Fei. (1961). A Theory of Economic Development. The American Economic Review, 51(4), 533-565.

9. Rath, Rishab, Kuldeep Mann and Amit Sharma (2008). "Ludhiana, Surat New Migration Hubs-Plus Points: Plenty of Jobs Going Around, No Xenophobes". Hindustan Times, 2-3-2008.

10. Singh, Manjit (1995). "Uneven Development in Agriculture and Labour Migration: A case of Bihar and Punjab". Indian Institute of Advanced Studies, Rashtrapati Bhawan, Shimla.

11. Singh, Manjit and Karan, Anup K. (2010), "Rural Labour Migration from Bihar", Institute for Human Development, New Delhi. 